\title{
Drying of microalga Spirulina platensis in a rotary dryer with inert bed
}

Silva, N. C.; Silva, T. C.; Santos, A. O.; Graton, I. S.; Duarte, C. R.; Barrozo, M. A. S. School of Chemical Engineering, Federal University of Uberlandia, Uberlandia, Minas Gerais, Brazil.

*E-mail of the corresponding author: masbarrozo@ufu.br

\begin{abstract}
The aim of this work is investigate the use of a rotary dryer with inert bed for drying of microalga Spirulina platensis. The influence of air temperature, feed rate, rotation speed and inerts filling degree was quantified. The contents of main bioactive compounds were also analyzed. The results shown that the used drying system proved to be an interesting alternative for a possible use of this microalga, if performed under adequate conditions. It was identified conditions with high drying performance and with the preservation of product quality.
\end{abstract}

Keywords: Spirulina platensis; rotary dryer; inert bed; bioactive compounds. 


\section{Introduction}

Spirulina platensis is one of the species of cyanobacterium microalgae that has gaining recent attention because of its nutritional and medicinal properties. Several studies reported the potential use of Spirulina biomass due the high presence of proteins, vitamins, minerals, antioxidant and anti-inflammatory compounds as the phycocyanin ${ }^{[1,2,3]}$. Despite this, the Spirulina is very perishable due its high moisture content that contributes to degradation, hamper transport and storage, and reduce the shelf life. Thus, it is necessary apply a drying technique that allows use properly this material in food or pharmaceutical industries.

The most traditional methods used to drying microalgae are spray drying, freeze-drying, solar drying and convective hot air drying ${ }^{[4,5]}$. However, the rotary dryers appears as an interesting alternative because their flexibility and high processing capacity. Conventional rotary dryers have flights, which lift solids and make them cascade across the dryer section. Most of the drying occurs during the free fall of solids from the flights, because of the large gas-solids surface contact area ${ }^{[6]}$. However, conventional rotary dryers are typically used for granular materials and are not suitable for pastes. Thus, the use of an inert bed (as metal or ceramic spheres, for example) is an interesting alternative for paste drying in rotary drums, since the inert increase the contact surface between hot air and material, and prevents the loss of material on the walls and dryer structures ${ }^{[7,8]}$.

In the present work, the drying of Spirulina platensis in a rotary dryer with inert bed was investigated. The effects of process variables on the drying yield was quantified and the impacts of these variables on the main bioactive compounds contents (total phenolics, total flavonoids, citric acid and phycocyanin) were also analyzed.

\section{Materials and Methods}

\subsection{Raw material}

The microalga Spirulina platensis used in this study was provided by the company Brasil Vital, located in the state of Goias, midwest Brazil. The material was previously filtered in vacuum, stored in small portions and frozen in a freezer.

\subsection{Experimental apparatus}

The experimental apparatus, shown in Fig. 1, consists of: a radial blower (Kepler-Weber, $112 \mathrm{M}$ ), an electric heater connected to a voltage variator to adjust the air temperature, the rotary drum coupled a rotation system composed by a motor and frequency inverter (WEG, CF08) to control the rotation speed, and a Stairmand cyclone separator (diameter $10 \mathrm{~cm}$ ) with a flask in its underflow to collect the dried material. The Spirulina in natura were fed in the system with a peristaltic pump (Masterflex, 7553-70) connected to a velocity variator. 
The rotary drum used in this study was a stainless steel cylinder with $12 \mathrm{~cm}$ of inner diameter and $36 \mathrm{~cm}$ of length. Three stainless flights with $2.5 \mathrm{~cm}$ are also placed into the drum for uniform axial distribution of inerts during the drying. The inerts particles used were porcelain spheres with diameter of $1.9 \mathrm{~cm}$ and density of $2.32 \mathrm{~g} / \mathrm{cm}^{3}$.

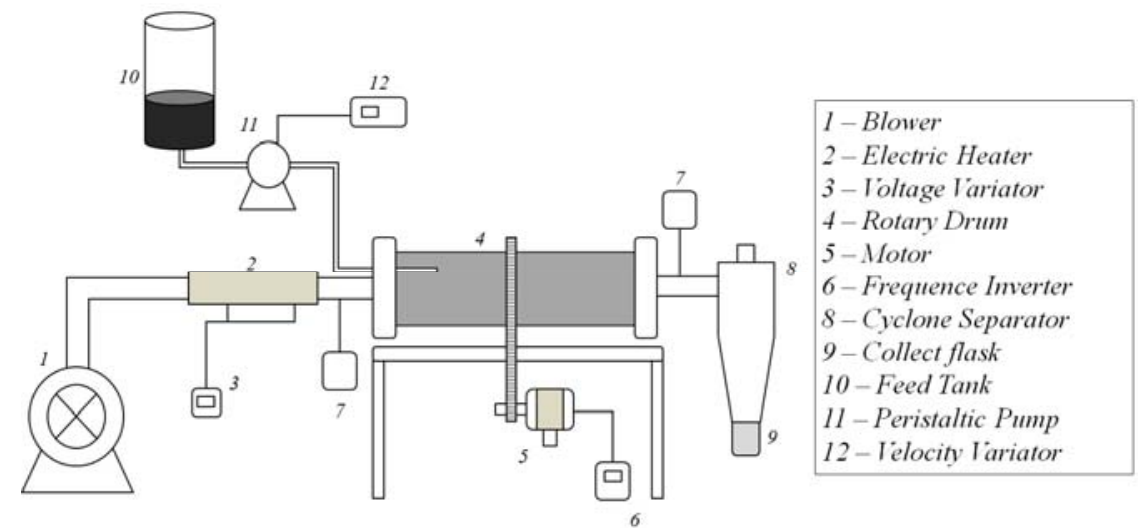

Fig. 1 Experimental apparatus.

\subsection{Experimental design}

The experiments were conducted following a orthogonal central composed design with four independent variables and two replicates at the center level, totaling 26 experiments. The independent variables analyzed were: the air temperature (T), feed intermittence (FI), inert filling degree (FD) and rotation speed (RS). In each experiment were used about $100 \mathrm{~g}$ of Spirulina microalga. The coded and real variable values are shown in Table 1.

Table 1. Coded and real variable values

\begin{tabular}{cccccc}
\hline Design Factors & -1.483 & -1 & 0 & +1 & +1.483 \\
\hline Air temperature $\left({ }^{\circ} \mathrm{C}\right)$ & 40.3 & 50.0 & 70.0 & 90.0 & 99.7 \\
Feed Rate (min) & 2.6 & 5.0 & 10.0 & 15.0 & 17.4 \\
Filling Degree (\%) & 12.1 & 15.0 & 21.0 & 27.0 & 29.9 \\
Rotation Speed (RPM) & 35.2 & 40.0 & 50.0 & 60.0 & 64.8 \\
\hline
\end{tabular}

The Air Temperature (T) was measured at the inlet of the drum. The wet Spirulina was fed in cycles, in an intermittent system of feed of $10 \mathrm{~g}$ of material and a rest for a determined 
time (defined as the variable Feed Intermittence). The Filling Degree (FD) was calculated based in the cylinder geometry and the properties of inert bed, as density and porosity, and the rotation speed (RS) were measured using a digital tachometer. The response studied was the Drying Yield (DY), that is the percentage ratio of the quantity of material (dry base) collected in the cyclone underflow to the quantity of microalga fed into the dryer (in dry base).

\subsection{Analysis of bioactive compounds}

The experiments with the highest values of Drying Yield (DY) had their bioactive compounds analyzed to evaluate the impact of the operational conditions on the quality of the final product. The total phenolics content (TPC) was determined by the FolinCiocalteau method ${ }^{[9]}$. The total flavonoids content (TFC) was determined using the method described by Zhishen et al. ${ }^{[10]}$. The acidity (CA), expressed in the presence of citric acid in the samples, was determined by AOAC ${ }^{[11]}$ method. The phycocyanin content (PC). was performed based on the methodology of Costa et al. ${ }^{[2]}$.

\section{Results and Discussion}

\subsection{Analysis of dehydration yield (DY)}

The most significant operating variables can be observed in Equation 1, through the parameters obtained by the multifactor ANOVA $\left(\mathrm{R}^{2}=0.9048\right.$ and $\left.\alpha=0.10\right)$. The effect of the studied variables on the drying yield can be visualized in Figure 2.

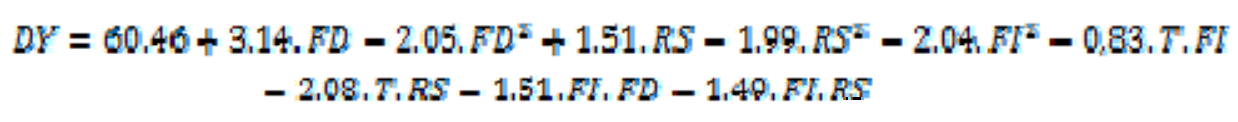


(a)

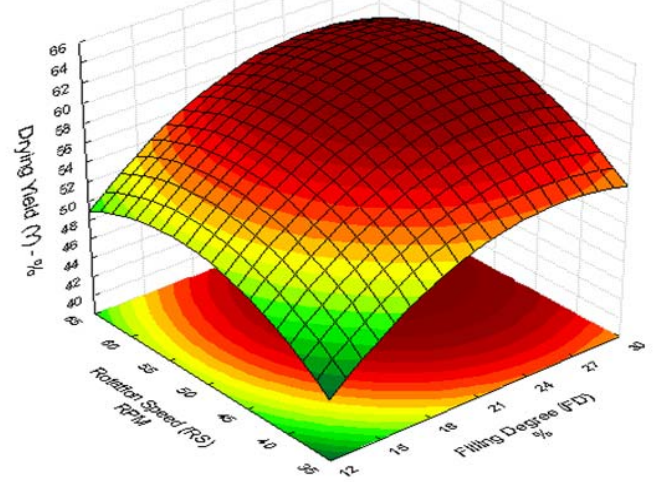

(c)

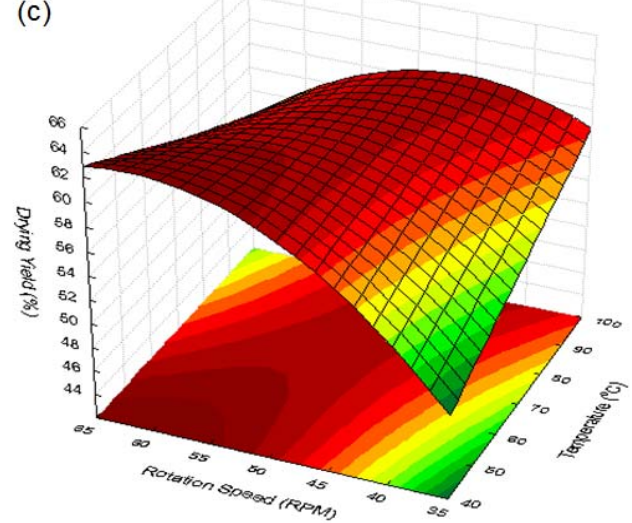

(b)

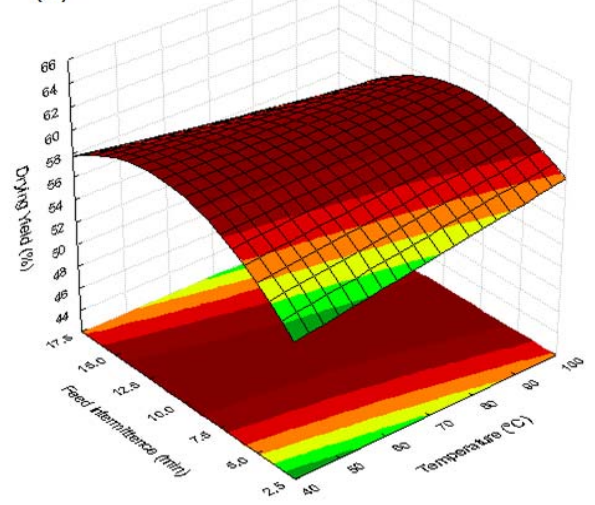

(d)

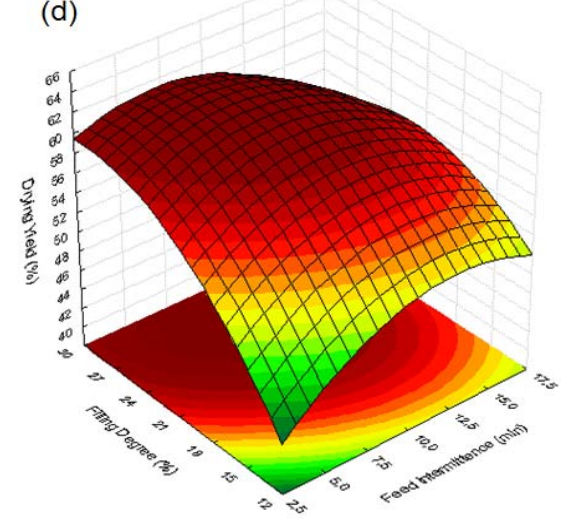

Fig. 2 Drying Yield (DY) response surfaces.

The variables: filling degree (FD) and rotation speed (RS) presented non linear effects on the DY (Equation 1 and Figure 2a). In general, the experiments performed at higher values of these variables produced a great quantity of dried material, hence the best results of DY. The effect of the temperature on DY was present by means of the interation with intermittence (FI) and rotation speed (RS). The best results were obtained with the association of low temperatures and high levels of RS or with intermediate levels of RI, as can be seen in Figure $2 \mathrm{~b}$ and Figure 2c.

The analysis of the results showed that the higher drying yields can be obtained in experimental conditions of high Filling Degree (FD) and Rotation Speed (RS), combined with Intermediate Feed Intermittences (FI) and low process Temperatures (T). For the 
conditions of the experimental design, the highest values of DY were obtained in the Experiments expressed in the Table 2.

Table 2. Experiments with the highest Drying Yields (DY)

\begin{tabular}{cccccc}
\hline Experiments & $T\left({ }^{\circ} \mathrm{C}\right)$ & $F R(\mathrm{~min})$ & $F D(\%)$ & $R S(R P M)$ & $D Y(\%)$ \\
\hline 4 & 50.0 & 5.0 & 27.0 & 60.0 & $63.28 \%$ \\
8 & 50.0 & 15.0 & 27.0 & 60.0 & $60.12 \%$ \\
17 & 40.3 & 10.0 & 21.0 & 50.0 & $61.88 \%$ \\
24 & 70.0 & 10.0 & 21.0 & 64.8 & $60.42 \%$ \\
\hline
\end{tabular}

\subsection{Analysis of Bioactive Compounds}
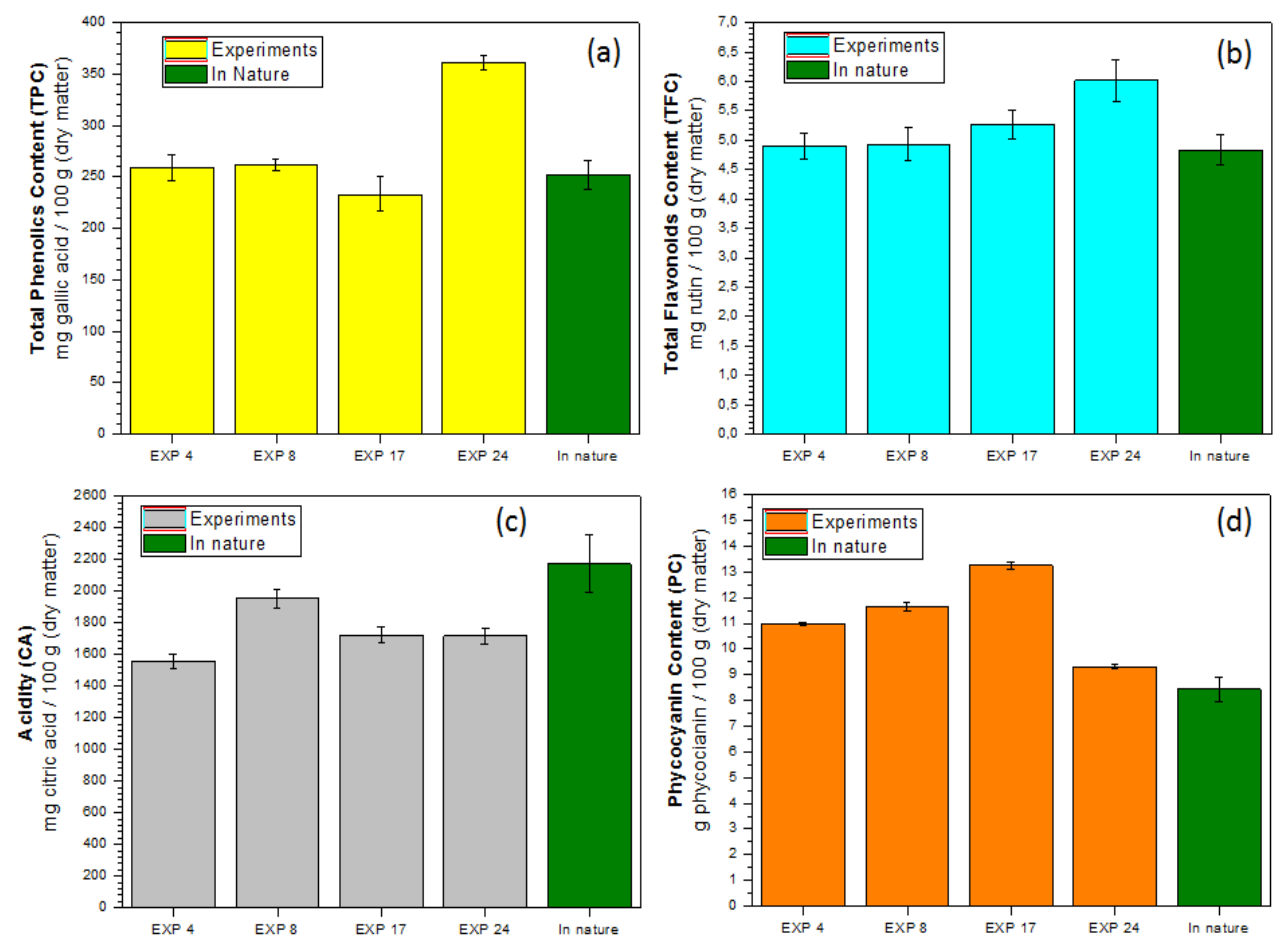

Fig. 3 Bioacitve compounds content in the experiments with the highest Drying Yield (DY).

The bioactive compounds content obtained in the four experiments showed in Table 2 are presented in Figure 3. It can be observed that for the experiments performed in the 
conditions that led the greatest yields, the main bioactive compounds were preserved, indicating that this drying methodology has good effect on the quality of final dried Spirulina. This bioactive content behavior was also also related by Chism \& Haard ${ }^{[12]}$ that observed the liberation of these compounds accumulated in vegetal cell organelles as vacuoles, due to rupture in the internal structure of the material during the moisture removal. Dorta et al. ${ }^{[13]}$ also claimed that inactivation of certain enzymes responsible for the degradation of bioactive compounds can occur during the drying process, resulting in their preservation.

\section{Conclusions}

The drying of microalga Spirulina platensis using a rotary dryer proved to be an interesting alternative for use of this material. All the variables analised showed statistical significance in the results of yield. The combination of low temperatures, high filling degree, high rotation speed and intermediate feed intermittence allowed obtain the highest drying yields. It was also possible obtain bioactive compounds content near than present in fresh biomass in the experiments analyzed, indicating a positive effect of this process of moisture removal on the final quality of dried product.

\section{References}

[1] Agustini, T.W.; Suzery, M.; Sutrisnanto, D.; Ma'ruf, W.F.; Hadyanto. Comparative Study of Bioactive Substances Extracted from Fresh and Dried Spirulina sp. Procedia Enviromental Sciences 2015, 23, 282-289.

[2] Costa, B.R.; Rodrigues, M.C.K.; Rocha, S.F.; Pohndorf, R.S.; Larrosa, A.P.Q., Pinto, L.A.A. Optimization of Spirulina Sp. Drying in Heat Pump: Effects on the Physicochemical Properties and Color Parameter. Journal of Food Processing and Preservation 2016, 40, 934-942.

[3] Dissa, A.O.; Desmorieux, H.; Savadogo, P.W.; Segda, B.G.; Koulidiati, J. Shrinkage, porosity and density behavior during convective drying of spirulina. Journal of Food Engineering 2010, 97, 410-418.

[4] Oliveira, E.G.; Rosa, G.S.; Moraes, M.A.; Pinto, L.A.A. Characterization of thin layer drying of Spirulina platensis utilizing perpendicular air flow. Bioresource Technology 2009, 100, 1297-1303.

[5] Show, K.Y.; Lee, D.J.; Chang, J.S. Algal biomass dehydration. Bioresource Technology 2013, 135. 720-729.

[6] Silva, P.B., Duarte, C.R., Barrozo, M.A.S. Dehydration of acerola (Malpighia emarginata D.C.) residue in a new designed rotary dryer: Effect of process variables on main bioactive compounds. Food and Bioproducts Processing 2016, 98, 62-70.

[7] Honorato, G.C. Design of a Rotary Dryer for Shrimp Cephalothorax Drying. Federal University of Rio Grande do Norte, Brazil, 185p., 2006 (Doctoral Thesis).

[8] Moura, B.D. Study of Drying Dynamics in a Rotary Dryer with Intermittent Feeding. 
Federal University of Rio Grande do Norte, Brazil, 123p., 2016 (Doctoral Thesis).

[9] Singleton V.L.; Rossi J.A. Colorimetry of total phenolics with phosphomolibidicphosphotungistic acid reagents. American Journal of Enology and Viticulture 1965, $16,144-158$.

[10] Zhishen J.; Mengcheng, T.; Jianming, W. The determination of flavonoid contents in mulberry and their scavenging effects on superoxide radicals. Food Chemistry 1999, $64,555-559$.

[11] AOAC, Association of Official Analytical Chemists. Official methods of analysis. Gaithersburg, MD: AOAC 1995.

[12] Chism, G.W.; Haard, N.F. Characteristics of edible plant tissues. In: O.R., Fennema, Food Chemistry 1996, 943-1011, New York, Marcel Dekker, Inc.

[13] Dorta, E.; Lobo, M.G.; Gonzalez, M. Using drying treatments to stabilise mango peel and seed: effect on antioxidant activity. LWT - Food Science and Technology 2012, $45,261-268$. 